\title{
Vaginal Birth After Previous Caesarean Section
}

\author{
Chro N. Fattah \\ University of Sulaimani, \\ College of Medicine, Obstetrics \& \\ Gynecology Dept., \\ Sulaimani, Iraq \\ chro.fattah@univsul.edu.iq
}

\author{
Hazha Jalal \\ Maternity Teaching Hospital, \\ Health sector, Obstetrics \& Gynecology \\ Dept., \\ Sulaimani, Iraq \\ hazhajt@hotmail.com
}

\begin{abstract}
The proportion of women who attempt vaginal birth after prior cesarean delivery has decreased mainly because of the concern about safety. The purpose of this study is to observe maternal \& neonatal outcomes in women delivered either by vaginal birth after caesarean section, elective repeat caesarean section or failed trial of labour. To design a definite protocol for selection of patient to achieve successful vaginal birth after caesarean (VBAC) section. A prospective observational study was set at Sulaimani Maternity Teaching Hospital/ Kurdistan region of Iraq, from first July 2013 to first July 2014. In which 200 pregnant women (with one prior caesarean section \& singleton, term, cephalic presentation) were enrolled, followed up during labour \& puerperium for maternal \& neonatal complications. Data analysis was performed using the statistical software namely (SPSS version 20). Planned vaginal birth was successful in $63.4 \%$ of pregnant women, with the least maternal and neonatal complication, apart from 3rd degree perineal tear (2.3\%) which was statistically significant (probability value $<0.001$ ). In conclusion, the women who had successful vaginal birth after caesarean, had better result for the mother and neonate than failed trial of labour and those who had elective repeat caesarean section. Women with body mass index of $<30 \mathrm{~kg} / \mathrm{m} 2$, age $<30$ years, inter pregnancy interval >18months, non-recurrent cause of previous scar and estimated fetal weight of $<4 \mathrm{~kg}$, had more successful VBAC rate.
\end{abstract}

Key words: Pregnant women, prior caesarean section, vaginal birth, planned elective repeat caesarean section.

\section{INTRODUCTION}

Trial of labor is a planned attempt to labour by a woman who has had a previous cesarean delivery, also known as trial of labour after cesarean (TOLAC), and a successful trial of labour is termed as vaginal birth after cesarean delivery (VBAC). (NIH, 2010; ACOG, 2010) [1].

For more than 30 years, planned (VBAC) has been offered as an option to women with prior caesarean section $(\mathrm{C} / \mathrm{S})$. This was mainly driven by the need to lower the rising rates of repeated $\mathrm{C} / \mathrm{S}$ following a previous C/S [2] (90\% in US, $83 \%$ in Australia \& $28 \%$ in UK), [3] and elimination of the need for major surgery which consequently reduces maternal and neonatal morbidity and mortality as well as reduce the financial and psychosocial disadvantages [4]. VBAC was therefore seen as an acceptable alternative to elective repeat caesarean section (ERCS). This approach was partially motivated by the reported success rates and safety of VBAC. Recent demographic data indicate that the practice of planned VBAC is now prevalent also in developing countries [2], and it was $82.15 \%$ in Batool Hospital in Mosul/Iraq in 2010 [5].

Vaginal birth after caesarean (VBAC) is considered to be a safe option for most women who have had a previous C/S [1]. For women who attempt a VBAC, the chance of achieving vaginal birth has been variably reported between $56 \%$ and $80 \%$ [6]. The proportion of women attempting a VBAC has been declining in many countries [3], fuelled by negative reports of an increase in the risk of maternal and fetal complications related to VBAC, including uterine rupture and perinatal death [7].

Women with a previous Caesarean section who undergo induction of labour are considered to have an increased risk of repeat Caesarean section compared with those that come with spontaneous labour. One systematic review showed that women with a previous $\mathrm{C} / \mathrm{S}$ have a risk of repeat caesarean delivery of $24 \%$ during a spontaneous labour but a risk of $48 \%$ following induction of labour with prostaglandin E2 (PGE2) [8].

To obtain the lowest neonatal respiratory morbidity [9]. If an elective $\mathrm{C} / \mathrm{S}$ is the decided mode of delivery, the operation is performed when the gestational period is greater than 38 weeks, The rate of respiratory distress syndrome (RDS) or transient tachypnea of neoborn (TTN) is $8.2 \%$ at $37 \mathrm{Wk}$., $5.5 \%$ at $38 \mathrm{Wk} ., 3.4 \%$ at $39 \mathrm{Wk} .3 \%$ at $40 \mathrm{Wk}$. of gestation [10]. On the other hand it has long been recognized that a pregnancy which goes beyond 40 weeks is associated with increased perintal mortality and morbidity like stillbirth, neonatal death, meconium staining of the amniotic fluid, intrapartum fetal hypoxia, fetal acidosis, neonatal seizure, birth trauma and shoulder dystocia [11].

In comparing (ERCS) with (VBAC), appropriate counseling should be undertaken in planning the mode of the delivery [11]. Maternal mortality rate is higher for (ERCS) than vaginal birth (5.9 for elective $\mathrm{C} / \mathrm{S}$ versus 18.2 for emergency $\mathrm{C} / \mathrm{S}$ versus 2.1 for vaginal birth, per 100000 completed pregnancies in UK. During 1994-1996) [12], Prolonged recovery, Future pregnancies would probably require $\mathrm{C} / \mathrm{S}$ for delivery, 
increased risks of placenta praevia and accreta in subsequent pregnancies [11], operative complications such as lacerations and bleeding may occur, at rates varying from $6 \%$ for elective $\mathrm{C} / \mathrm{S}$ to $15 \%$ for emergency $\mathrm{C} / \mathrm{S}$ [12]. Fetal risks; Increased risk of RDS \& TTN which is $8.2 \%$ at $37 \mathrm{Wk}$., $5.5 \%$ at $38 \mathrm{Wk} ., 3.4 \%$ at $39 \mathrm{Wk}$. $3 \%$ at $40 \mathrm{Wk}$. of gestation [10], also a recent study has reported that the risk of unexplained stillbirth in a second pregnancy is somewhat increased if the first birth was by $\mathrm{C} / \mathrm{S}$ rather than by vaginal delivery (1.2 per 1000 versus 0.5 per 1000). Lastly birth by $\mathrm{C} / \mathrm{S}$ is not generally considered natural or normal [12]. It is recommended to repeat $\mathrm{C} / \mathrm{S}$ for women with previous classical incision. A scar rupture rate of $12 \%$ has been seen in this group. Lower segment vertical scars are associated with lower rates of uterine ruptures of $2 \%$. Women with a low uterine scar should be considered for VBAC. J-shaped and inverted $\mathrm{T}$-shaped incisions are associated with similar rupture rates to low vertical incisions (1.9\%) [11].

Magnetic resonance imaging studies of myometrial healing suggest that complete uterine involution and restoration of anatomy may require at least 6 months [10]. Inter delivery interval of 18 months or less were associated with a threefold increased risk of symptomatic rupture during a subsequent trial of labour compared with intervals greater than 18 months. Similarly, Stamilio and co-workers (2007) noted a threefold increased risk of uterine rupture in women with an inter delivery interval of less than 6 months compared with one of 6 months or longer [10].

Obesity appears to increase the risk of inefficient uterine activity [11], body mass index (BMI) greater than 30 associated with increased risk of unsuccessful VBAC [13]. Observational data suggest that for women weighing $>135 \mathrm{~kg}$, the chance of vaginal delivery is very low (13\%) [11], and ERCS may be a better option in this very obese group [13]. The success of vaginal birth in all women decreases as age increases. Studies have shown lower rates of successful VBAC in women over 35 years old [11]. Other risk factors include; fetal macrosomia [11], birth weight greater than $4000 \mathrm{~g}$ [1], induced labour, no previous vaginal birth, no epidural anaesthesia, previous preterm $\mathrm{C} / \mathrm{S}$ birth [1], delivery after 41 weeks, cervical dilatation of $<4 \mathrm{~cm}$ at admission, non-white ethnicity, male infant and short maternal stature [11].

\section{PATIENTS AND METHODS}

This study is a prospective observational study, carried out at Maternity Teaching Hospital in Sulaimani Kurdistan region/Iraq which is the main obstetric \& gynecological hospital in the city of Selamni city (Kurdistan region of Iraq) and its surrounding areas as a tertiary centre. The annual rate of childbirth in this hospital is 15000 with (28\%) by C/S This study was conducted in the period between (July.1st.2013) till (July.1st.2014), 200 pregnant women were enrolled;
Inclusion criteria: Singleton, term ( $\geq 37 \mathrm{wk}$ ), cephalic presentation, with only one lower segment caesarean section delivery, no medical disorder in the current pregnancy. . written consent was obtained from all the pregnant women.

Of these 200 pregnant women; 66 of them were scheduled for ERCS by decision of the C/S committee of the hospital, they were followed up intra operatively, post-operatively and puerperium by phone call \& advised them to visit hospital in case of suspected any maternal or neonatal adverse complication. While the remaining 134 pregnant women were referred from the outpatient clinic to labour ward for TOLAC. They were followed up during the entire process of labour. From these 134 pregnant women, 85 of them were achieved successful VBAC the rest 49 pregnant ladies were ended by failed TOL \& emergency $\mathrm{C} / \mathrm{S}$ done for them, all groups were followed up during labour ward stay, intraoperative, postoperative and puerperium similar to other groups.

The neonates of all groups were followed up by Apgar score, birth weight, need for immediate resuscitation( $1 \mathrm{st}$ min Apgar score <7), NICU admission(5th min Apgar score <7) \& NICU stay, birth trauma, respiratory distress, septicemia, seizure \& perinatal death during hospital stay and then after 4 weeks by phone call $\&$ advice their mother to bring them to the hospital in case of any suspected complication.

\section{Ethical considerations:}

This study was approved by the Research Ethical Committee of the Kurdistan Board for Medical Specializations Sulaimani, Iraq

\section{Data analysis:}

All data collected, analyzed using SPSS (Version 20 software) computer program. Statistical analysis included Chi-square test to compare between the quantitative variables in both groups (ERCS \& TOLAC). In this analysis the probability value (P-value) of $<0.05$ was considered statistically significant. 


\section{RESULTS}

In this study, two hundred, term, vertex presentation, singleton, previous one $\mathrm{C} / \mathrm{S}$ pregnant ladies were enrolled, and categorized in to two groups (A\&B) \& subgroups (A1\&A2) according to their modes of delivery;

Group A; TOLAC group, (134) pregnant ladies, (67\%) of the studied cases.

A1; successful VBAC, (85) pregnant ladies, $(42.5 \%)$ of the studied cases.

A2; Failed trial of labour FTOL, (49) pregnant ladies, $(24.5 \%)$ of the studied cases.

Group B; ERCS group, (66) pregnant ladies, (33\%) of the studied cases.

All maternal demographics, neonatal characteristics, maternal \& neonatal outcomes were compared with the mode of delivery (Table 1 ).
Most women of FTOL group (47\%) had inter pregnancy interval of less than 18 months, while most women that achieved successful VBAC (72.9\%) had longer inter pregnancy interval (more than 24 months), so the inter pregnancy interval in relation to the mode of delivery was considered statistically significant. The correlation between the cause of previous $\mathrm{C} / \mathrm{S}$ and mode of delivery was statistically significant $(\mathrm{P}$ value $=<0.001)$; in those who delivered by successful VBAC, the most common cause of their previous scar was breech presentation (28.2\%), in those who delivered by ERCS, the most common cause was prolonged pregnancy $(25.7 \%)$, while in FTOL group the most common cause was failure of progress $(28.5 \%)$ which is a recurrent cause. As shown in (Table 2).

There is significant correlation between the colour of liquor $\&$ the mode of delivery as highest incidence of clear liquor $(94.1 \%)$ was recorded in VBAC group while highest incidence of meconium stained liquor was found in FTOL group. (Table 3).

Table 1. Maternal demographic characteristics \& mode of delivery:

\begin{tabular}{|c|c|c|c|c|c|}
\hline \multirow{2}{*}{\multicolumn{2}{|c|}{$\begin{array}{l}\text { Variables } \\
\text { Frequency (\%) }\end{array}$}} & \multicolumn{2}{|l|}{ Group A } & \multirow{2}{*}{$\begin{array}{l}\text { Group B } \\
\text { Frequency (\%) }\end{array}$} & \multirow[b]{2}{*}{$\mathrm{P}$ value } \\
\hline & & $\begin{array}{l}\text { A1 } \\
\text { Frequency }(\%)\end{array}$ & $\begin{array}{l}\mathrm{A} 2 \\
\text { Frequency }(\%)\end{array}$ & & \\
\hline \multicolumn{5}{|c|}{ Age (year) } & \multirow{4}{*}{$<0.001$} \\
\hline$<20$ & $4(2 \%)$ & $0(0 \%)$ & $0(0 \%)$ & $4(6 \%)$ & \\
\hline $20-30$ & $113(56.5 \%)$ & $56(65.8 \%)$ & $13(26.5 \%)$ & $44(66.6 \%)$ & \\
\hline$>30$ & $83(41.5 \%)$ & $29(34.1 \%)$ & $36(73.4 \%)$ & $12(27.2 \%)$ & \\
\hline \multicolumn{5}{|c|}{ BMI. $\left(\mathrm{kg} / \mathrm{m}^{2}\right)$} & \multirow{6}{*}{$<0.001$} \\
\hline$<18$ & $2(1 \%)$ & $0(0 \%)$ & $2(4 \%)$ & $0(0 \%)$ & \\
\hline $18-24.9$ & $55(27.5 \%)$ & $36(42.3 \%)$ & $12(24.4 \%)$ & $7(10.6 \%)$ & \\
\hline $25-29.9$ & $111(55.5 \%)$ & $35(41.1 \%)$ & $26(53 \%)$ & $50(75.7 \%)$ & \\
\hline $30-34.9$ & $30(15 \%)$ & $12(14.1 \%)$ & $9(18.3 \%)$ & $9(13.6 \%)$ & \\
\hline$\geq 35$ & $2(1 \%)$ & $2(2.3 \%)$ & $0(0 \%)$ & $0(0 \%)$ & \\
\hline
\end{tabular}


Table 2. Obstetric characteristics and mode of delivery.

\begin{tabular}{|c|c|c|c|c|}
\hline \multirow{2}{*}{$\begin{array}{l}\text { Variables } \\
\text { Frequency }(\%)\end{array}$} & \multicolumn{2}{|l|}{ Group A } & \multirow{2}{*}{$\begin{array}{l}\text { Group B } \\
\text { Frequency (\%) }\end{array}$} & \multirow{2}{*}{$P$ value } \\
\hline & $\begin{array}{l}\text { A1 } \\
\text { Frequency }(\%)\end{array}$ & $\begin{array}{l}\mathrm{A} 2 \\
\text { Frequency }(\%)\end{array}$ & & \\
\hline \multicolumn{4}{|l|}{ Pregnancy interval / month } & \multirow{4}{*}{$<0.001$} \\
\hline $36(18 \%)$ & $9(10.6 \%)$ & $23(47 \%)$ & $4(6.1 \%)$ & \\
\hline $42(21 \%)$ & $14(16.5 \%)$ & $18(36.7 \%)$ & $10(15.1 \%)$ & \\
\hline $122(61 \%)$ & $62(72.9 \%)$ & $8(16.3 \%)$ & $52(78.8 \%)$ & \\
\hline Cause of previous $\mathrm{C} / \mathrm{S}$ : & & & & \multirow{10}{*}{$<0.001$} \\
\hline $45(22.5 \%)$ & $18(21.1 \%)$ & $14(28.5 \%)$ & $13(19.6 \%)$ & \\
\hline $43(21.5 \%)$ & $24(28.2 \%)$ & $11(22.4 \%)$ & $8(12.1 \%)$ & \\
\hline $26(13 \%)$ & $7(8.2 \%)$ & $9(18.3 \%)$ & $10(15.1 \%)$ & \\
\hline $25(12.5 \%)$ & $14(16.4 \%)$ & $4(8.1 \%)$ & $7(10.6 \%)$ & \\
\hline Prolonged pregnancy $21(10.5 \%)$ & $4(4.7 \%)$ & $0(0 \%)$ & $17(25.7 \%)$ & \\
\hline Meconium & $8(9.4 \%)$ & $5(10.2 \%)$ & $4(6 \%)$ & \\
\hline Fetal distress & $10(11.7 \%)$ & $6(9 \%)$ & $0(0 \%)$ & \\
\hline Cholestasis & $0(0 \%)$ & $0(0 \%)$ & $5(7.5 \%)$ & \\
\hline Infertility & $0(0 \%)$ & $0(0 \%)$ & $2(3 \%)$ & \\
\hline
\end{tabular}

Table 3. Current pregnancy characteristics and mode of delivery

\begin{tabular}{|c|c|c|c|c|}
\hline \multirow{2}{*}{$\begin{array}{l}\text { Variables } \\
\text { Frequency }(\%)\end{array}$} & \multicolumn{2}{|l|}{ Group A } & \multirow{2}{*}{$\begin{array}{l}\text { Group B } \\
\text { Frequency }(\%)\end{array}$} & \multirow[b]{2}{*}{$P$ value } \\
\hline & $\begin{array}{l}\text { A1 } \\
\text { Frequency }(\%)\end{array}$ & $\begin{array}{l}\mathrm{A} 2 \\
\text { Frequency }(\%)\end{array}$ & & \\
\hline \multicolumn{4}{|l|}{ GA / week } & \multirow{3}{*}{$<0.001$} \\
\hline $\begin{array}{ll}<39 & 82(41 \%)\end{array}$ & $35(41.1 \%)$ & $29(59.1 \%)$ & $18(27.2 \%)$ & \\
\hline$\geq 39 \quad 118(59 \%)$ & $50(58.9 \%)$ & $20(40.9 \%)$ & $48(72.8 \%)$ & \\
\hline \multicolumn{4}{|l|}{ Liquor } & \multirow{3}{*}{0.019} \\
\hline $\begin{array}{ll}\text { Clear } & 180(90 \%)\end{array}$ & $80(94.1 \%)$ & $39(79.6 \%)$ & $61(92.4 \%)$ & \\
\hline Meconium 20(10\%) & $5(5.9 \%)$ & $10(20.4 \%)$ & $5(7.6 \%)$ & \\
\hline
\end{tabular}


Table 4. Maternal complications and mode of delivery

\begin{tabular}{|c|c|c|c|c|}
\hline \multirow[b]{2}{*}{$\begin{array}{l}\text { Variables } \\
\text { Frequency }(\%)\end{array}$} & \multicolumn{2}{|l|}{ Group A } & \multirow[b]{2}{*}{$\begin{array}{l}\text { Group B } \\
\text { Frequency }(\%)\end{array}$} & \multirow[b]{2}{*}{$P$ value } \\
\hline & $\begin{array}{l}\mathrm{A} 1 \\
\text { Frequency }(\%)\end{array}$ & $\begin{array}{l}\mathrm{A} 2 \\
\text { Frequency }(\%)\end{array}$ & & \\
\hline PPH $\quad 9(4.5 \%)$ & $3(3.5 \%)$ & $4(8.1 \%)$ & $2(3 \%)$ & 0.359 \\
\hline Blood transfusion $6(3 \%)$ & $2(2.3 \%)$ & $4(8.1 \%)$ & $0(0 \%)$ & 0.185 \\
\hline UTI $\quad 5(2.5 \%)$ & $2(2.3 \%)$ & $2(4 \%)$ & $1(1.5 \%)$ & \multirow{3}{*}{0.671} \\
\hline Mastitis & $2(2.3 \%)$ & $1(2 \%)$ & $1(1.5 \%)$ & \\
\hline Endometritis & $0(0 \%)$ & $1(2 \%)$ & $0(0 \%)$ & \\
\hline Pneumonia & $0(0 \%)$ & $1(2 \%)$ & $0(0 \%)$ & 0.213 \\
\hline
\end{tabular}

Table 5. Maternal complications related to TOLAC group

\begin{tabular}{|c|c|c|c|}
\hline $\begin{array}{l}\text { Variables } \\
\text { Frequency (\%) }\end{array}$ & $\begin{array}{l}\text { VBAC } \\
\text { Frequency }(\%)\end{array}$ & $\begin{array}{l}\text { FTOL } \\
\text { Frequency }(\%)\end{array}$ & $P$ value \\
\hline $\begin{array}{ll}\text { Uterine rupture } & 1(0.7 \%)\end{array}$ & $0(0 \%)$ & $1(2 \%)$ & \multirow{3}{*}{$<0.001$} \\
\hline $\begin{array}{ll}\text { Open bladder } \quad 1(0.7 \%) \\
\end{array}$ & $0(0 \%)$ & $1(2 \%)$ & \\
\hline $\begin{array}{ll}\text { Perineal tear } & 2(1.4 \%)\end{array}$ & $2(2.3 \%)$ & $0(0 \%)$ & \\
\hline Vacuum delivery $10(7.4 \%)$ & $5(5.8 \%)$ & $5(10.2 \%)$ & 0.541 \\
\hline
\end{tabular}

Table 6. Neonatal characteristics and mode of delivery:

\begin{tabular}{|c|c|c|c|c|}
\hline \multirow{3}{*}{$\begin{array}{l}\text { Variables } \\
\text { Frequency (\%) }\end{array}$} & \multicolumn{2}{|l|}{ Group A } & \multirow{3}{*}{$\begin{array}{l}\text { Group B } \\
\text { Frequency (\%) }\end{array}$} & \multirow{3}{*}{$\mathrm{P}$ value } \\
\hline & A1 & $\mathrm{A} 2$ & & \\
\hline & Frequency $(\%)$ & Frequency $(\%)$ & & \\
\hline \multicolumn{4}{|l|}{ Baby weight / kg } & \multirow{3}{*}{$<0.001$} \\
\hline$\geq 4 \mathrm{~kg} \quad 25(12.5 \%)$ & $3(3.5 \%)$ & $14(28.5 \%)$ & $8(12.1 \%)$ & \\
\hline$<4 \mathrm{~kg} \quad 175(87.5 \%)$ & $82(96.5 \%)$ & $35(71.5 \%)$ & $58(87.9 \%)$ & \\
\hline \multicolumn{4}{|l|}{ Apgar score } & \multirow{3}{*}{$<0.001$} \\
\hline $1^{\text {st }} \min .<7 \quad 83(41.5 \%)$ & $35(41.1 \%)$ & $25(51 \%)$ & $23(34.8 \%)$ & \\
\hline $5^{\text {th }} \min .<7 \quad 11(5.5 \%)$ & $1(1.1 \%)$ & $10(20.4 \%)$ & $0(0 \%)$ & \\
\hline \multicolumn{4}{|l|}{ Gender } & \multirow{3}{*}{0.169} \\
\hline $110(55 \%)$ & $41(48.2 \%)$ & $27(55.1 \%)$ & $42(63.6 \%)$ & \\
\hline Female & $44(51.8 \%)$ & $22(44.9 \%)$ & $24(36.4 \%)$ & \\
\hline
\end{tabular}


Table 7. Neonatal complications and mode of delivery:

\begin{tabular}{|c|c|c|c|c|}
\hline \multirow{3}{*}{$\begin{array}{l}\text { Variables } \\
\text { Frequency }(\%)\end{array}$} & \multicolumn{2}{|l|}{ Group A } & \multirow{3}{*}{$\begin{array}{l}\text { Group B } \\
\text { Frequency }(\%)\end{array}$} & \multirow{3}{*}{$\mathrm{P}$ value } \\
\hline & 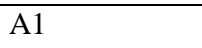 & $\mathrm{A} 2$ & & \\
\hline & Frequency $(\%)$ & Frequency $(\%)$ & & \\
\hline NICU admission $126(63 \%)$ & $11(12.9 \%)$ & $49(100 \%)^{*}$ & $66(100 \%)^{*}$ & $<0.001$ \\
\hline \multicolumn{5}{|l|}{ Causes of NICU admission: } \\
\hline Observation & $0(0 \%)$ & $17(34.7 \%)$ & $46(69.8 \%)$ & \multirow{6}{*}{0.062} \\
\hline $\mathrm{Rh}$ incompatibility & $2(2.4 \%)$ & $12(24.5 \%)$ & $11(16.6 \%)$ & \\
\hline Meconium & $5(5.9 \%)$ & $10(20.4 \%)$ & $5(7.6 \%)$ & \\
\hline Low Apgar & $1(1.1 \%)$ & $10(20.4 \%)$ & $0(0 \%)$ & \\
\hline Caput succedaneum $5(2.5 \%)$ & $1(1.1 \%)$ & $0(0 \%)$ & $4(6 \%)$ & \\
\hline Shoulder dystocia & $2(2.4 \%)$ & $0(0 \%)$ & $0(0 \%)$ & \\
\hline \multicolumn{4}{|l|}{ NICU. stay: } & \multirow{3}{*}{$<0.001$} \\
\hline $106(53 \%)$ & $10(11.7 \%)$ & $38(77.5 \%)$ & $58(87.8 \%)$ & \\
\hline $20(10 \%)$ & $1(1.1 \%)$ & $11(22.4 \%)$ & $8(12.1 \%)$ & \\
\hline Need for resuscitation $16(8 \%)$ & $4(4.7 \%)$ & $11(22.4 \%)$ & $1(1.5 \%)$ & $<0.001$ \\
\hline Perinatal death & $0(0 \%)$ & $1(2 \%)$ & $0(0 \%)$ & 0.541 \\
\hline Respiratory distress $7(3.5 \%)$ & $1(1.1 \%)$ & $4(6 \%)$ & $2(3 \%)$ & 0.102 \\
\hline Septicemia & $0(0 \%)$ & $2(3 \%)$ & $0(0 \% \%)$ & 0.044 \\
\hline Seizure & $0(0 \%)$ & $2(3 \%)$ & $0(0 \%)$ & 0.044 \\
\hline
\end{tabular}

\section{DISCUSSION}

The absolute and relative risks associated with a TOL as compared with ERCS delivery without labour are uncertain [14]. The majority of women with an uncomplicated first $\mathrm{C} / \mathrm{S}$, in an otherwise uncomplicated pregnancy, are candidates for attempting $\operatorname{VBAC}[1,20]$. in recent years, there has been a reported decline in the use of VBAC in several countries $[15,16]$.

In the USA, the overall rate of VBAC (i.e. successful VBAC/all women with a previous caesarean section) decreased from $24 \%$ in 1996 to $8 \%$ in 2010. This downward trend, accompanied by rising rates of primary $\mathrm{C} / \mathrm{S}$, has been a significant driver of the overall $\mathrm{C} / \mathrm{S}$ rate, which continues to cause widespread public and professional concern [16].

Analyzing maternal age in to three groups, women who were $>30$ years old, were more likely to experience an unsuccessful trial of labour. There is a trend that older women are less likely to attempt VBAC and more likely to have a FTOL because of increasing obstetrical complications on one hand and fibrosis of uterine muscle on the other hand. This is comparable with the studies done by (Beena D. Kamath et. al 2009) [16] and (Cristina Rossi et. al 2008) [17]. Maternal obesity is a well-known risk factor for caesarean delivery $[19,20]$. It has also been reported by some authors that maternal underweight has a protective effect $[21,22]$. Others have emphasized the role of short stature $(<1.55 \mathrm{~m})$ as a highrisk factor [22]. Current study demonstrated that BMI was directly associated with FTOL, this relationship was shown by several previous studies like; [13] \& (Cristina Rossi et. al 2008) [17], a study done by (G Barau et. al in 2006 at Carolina University) demonstrated that very lean women (BMI 10-14) were more likely to deliver vaginally than lean women ( BMI 15 - 19.9) and more likely than women with normal BMI [18]. Ravindu P. Guantilake et.al [19] demonstrated that the risk for caesarean delivery increases as BMI increases > 40 among nulliparous extremely obese women attempting a trial of labor, further increases in BMI > 40 among parous women attempting a TOL does not seem to add additional risk for cesarean delivery [24]. 
Current study revealed that the least inter pregnancy interval ( $<18$ months) was associated with failed VBAC, which is comparable with Huang and colleagues [25] study (reviewed 1.516 patients who underwent VBAC and found that an inter delivery interval of less than 19 months was associated with a decrease rate of successful VBAC). In contrast, Bujold and colleagues, reviewed 1.527 women attempting VBAC and found that an inter delivery interval of 24 months or less was associated with no difference in VBAC success rates [21].

The indication of previous $\mathrm{C} / \mathrm{S}$ had also an influence on the success rate of the trial for VBAC, Our data clearly shows that those who had a previous cesarean delivery for a nonrecurring indication like breech, CTG abnormalities or meconium stained liquor are more likely to have a successful VBAC attempt, while those who had a recurring indication like Fialure of progress (FOP) are more likely to end by FTOL. The same result was founded by (Gyamfi et. al 2004) [22].

American College of Obstetricians \& gynecologists recommends scheduling elective $\mathrm{C} / \mathrm{S}$ at 39 weeks or later based on menstrual date and first trimester ultrasound [28]. In this study more than two-third (72.8\%) of elective cesarean deliveries were performed at 39 weeks or later which is comparable with a study done in the United States on the timing of ERCS delivery at term, Tita et al. [29], found that $(64.2 \%)$ of elective repeat caesarean section was performed after 39 completed weeks of gestation, while current study is incomparable with the study done by Okeke TC et. al, where $(71.3 \%)$ of elective cesarean were done before 39 completed weeks of gestation [30], compared to Netherlands where $(56.6 \%)$ of elective caesarean were done before 39 completed weeks [31]. The rates of elective C/S delivery before 39 weeks were higher in the European cohorts (ranging from 51 to $83 \%$ ) [32].

The overall incidence of maternal complications like PPH, blood transfusion, UTI, endometritis \& pneumonia was slightly higher in women of FTOL group but with no significant difference. Similar finding was demonstrated by (Gymfi et. al 2004), [27] (Sharon et. al 2004) [14]. While (Shiliang Liu et. al 2007) founded that the planned ERCS group had increased risk of postpartum bleeding, blood transfusion $\&$ infections than VBAC group [28]

The incidence of serious maternal complications like uterine rupture $(0.7 \%) \&$ open bladder $(0.7 \%)$ was significantly higher in women who had emergency $\mathrm{C} / \mathrm{S}$ for FTOL. Similar findings was reported by previous studies but with different incidence; (Michael F. Green et. al 2004) [29] reported 0.7\%, (Cristina Rossi et.al 2008) [17] reported 4.4\%, (Alison G. et. al 2006) [30] reported $0.9 \%$. In contrast (George O Ugwu et. al 2014, recorded no case of uterine rupture in his study [31].

Our series revealed that baby's birth weight less than $4 \mathrm{~kg}$ was clearly associated with successful VBAC. Similar finding was reported by (Landon et. al 2004) [12], (Simpson L.et. al 2003) suggested that women with macrosomic infant should retrain from attempting VBAC [32]

An Apgar score $<7$ at 5 minute was highest in (20.4\%) of FTOL group in compare to VBAC \& ERCS group which was $(1.1 \%),(0 \%)$ respectively.

In contrast (Guise JM et.al 2010) [33] in his study, demonstrated that there are no significant differences in five-minute Apgar scores or NICU admissions, when infants who delivered by TOLAC compared with those delivered by ERCS [35]

There was one perinatal death in this study, which was occurred in TOLAC group due to rupture uterus \& severe intrapartum asphyxia, ERCS as planned mode of birth is significantly associated with a lower risk of both stillbirth and neonatal death in comparison with TOLAC group. For women planning a VBAC, our $0.7 \%$ risk of perinatal death is similar to that reported from previous cohort studies that compared actual rather than planned mode of birth where risks ranges between $0.13 \%$ and $2.4 \%$ [7, 34]. We believe Further multicentre randomized controlled study with a larger number of data \& longer term follow up will need to determine the fetal outcome \& long term maternal morbidity in the term of subsequent complications of morbidly adherent placenta, maternal mortality \& infertility. .Most women should be offered Frequent \& adequate advice about VBAC and offered TOL Provided that there are no contraindications \& facilities available for emergency caesarean section, in the presence of skilled health professional \& well equipped labour ward \& theater

\section{CONCLUSIONS}

Planned VBAC is successful in $(63.4 \%$; approximately $2 / 3$ rd) of pregnant women. and had better maternal \& neonatal outcomes than ERCS \& FTOL.Women with BMI of $<30$, age $<30$ years, long inter pregnancy interval ( $>18$ months), non-recurrent cause of previous scar \& estimated fetal weight of $<4 \mathrm{~kg}$ have more successful VBAC rate.

\section{ACKNOWLEDGMENT}

A special thanks to Sulaimani Maternity Teaching Hospital manager, for helping me to conduct my study there. My gratitude goes to Dr. Sinor K. Kokoii, who helped me in analyzing the data.Special thanks for the entire pregnant ladies who involved in this study, in which without them I couldn't do this

\section{REFERENCES}

[1] Royal College of Obstetricians and Gynecologists, "Green-top Guideline. Birth after previous caesarean birth Guideline February," 2007.

[2] SZ. Wanyoni, SK. Ngichabe, "Safety concern for planned vaginal birth after caesarean section in Sub-Sahran Africa," BJOG, vol. 121, pp. 141144, 2014. 
[3] BE. Hamilton, JA. Martin \& Ventura, "Vaginal Birth After Caesarean," Natl.Vital Stat Rep, vol. 57, pp. 1-102, 2009.

[4] EJ. Kang, KA. Lee, MH. Park, YJ. Kim, SH. Chun, JJ. Ahn, "Evaluation of the factors affecting the success of the trial of vaginal birth and duration of labor in women with previous cesarean section," Korean J Obstet Gynecol, vol. 50, pp. 1640-49, 2007.

[5] M. Raida Al-Wazzan, "Factors affecting success of trial of labour after previous one lower segment Caesarean section," Department of Obstetrics \& Gynecology, College of Medicine, University of Mosul, Annals of the College of Medicine, vol. 36 ,pp. 121-129, 2010.

[6] A. Aisien, A. Oronsaye, "Vaginal birth after one previous Caesarean section in a tertiary institution in Nigeria," J Obstet Gynecol, vol.24, pp. 886-90, 2004.

[7] E. Wall, R. Roberts, M, Deutchman, W, Hueston, L. Atwood and B. Ireland, "American Academy of Family Physicians. Trial of labour after caesarean (TOLAC)," Formerly trial of labour versus elective repeat caesarean section for the women with a previous caesarean section ,AAFP Policy Action March, 2005.

[8] 8Society of Obstetricians and Gynecologists of Canada, "SOGC clinical practice guidelines, Guidelines for vaginal birth after previous caesarean birth," Int J Gynecol Obstet, vol. 89, pp. 319-31, 2005.

[9] S. Chhabra, G. Arora, "Delivery in women with previous caesarean section," J Obstet Gynecol India, vol. 56, pp. 304-7, 2006.

[10] SK1. Srinivas, DM. Stamilio, MD. Sammel, EJ. Stevens, JF, Peipert, AO. Odibo, et al., "Predicting failure of a vaginal birth attempt after caesarean delivery," Obstet Gynecol, vol. 109, pp. 800-5, 2007.

[11] M. Dinsmoor, and E. Brock, "Predicting failed trial of labour after primary caesarean delivery," Obstet Gynecol, vol. 103, pp. 282-6, 2004.

[12] MB. Landon, JC. Hauth, KJ. Leveno, "Maternal and perinatal outcomes associated with a trial of labor after prior cesarean delivery," NEJM, vol. 351, pp. 2581-2589, 2004.

[13] F. G. Cunningham, J. Kenneth, L. Steven \& B. Williams, "Obstetrics, Twenty-Third Edition, USA, Chapter 26,” vol. 12, pp. 1404, 2010.

[14] JR. Scott, “Avoiding labour problems during vaginal birth after caesarean delivery," Clin Obstet Gynecol, vol 40, pp. 533-41, 1997.

[15] M. MacDorman, E. Declercq, F. Menacker, "Recent trends and patterns in cesarean and vaginal birth after cesarean (VBAC) deliveries in the United States," Clin Perinatol, vol.38, pp. 179-92, 2011.

[16] D. Beena, K. James, E. Judith, Glazner, D. Lezotte, , and M. Anne, "Neonatal outcomes after elective caesarean delivery," University of Colorado school of medicine, 2009.

[17] C. Rossi, D. Vincenzo \& Addario, "Maternal morbidity following a trial of labor after cesarean section vs elective repeat cesarean delivery," University of Bari, Bari, Italy, 2008.

[18] G Barau, P-Y Robillard, TC Hulsy, "Linear association between maternal pre- pregnancy BMI and risk of caesarean section in term deliveries," University of South Carolina, RCOG, 2006.

[19] P. Ravindu, P. Michael, B, Harris, "Predictors of failed trial of labor among women with an extremely obese BMI," University of North Carolina, AJOG, 2013.

[20] WH. Huang, DK. Nakashima, PJ. Rumney, KA. Keegan, K. Chan, "Interdelivery interval and the success of vaginal birth after cesarean delivery," Obstet Gynecol, vol. 99, pp. 41-4, 2002.

[21] E. Bujold, SH. Mehta, C. Bujold, RJ. Gauthier, "Interdelivery interval and uterine rupture," AJOG, vol.187, pp. 1199-202, 2002.

[22] G., Cynthia, J. Gabor, P. Stone, L. Joanne, "Increased success of trial of labor after previous vaginal birth after cesarean," The Mount Sinai Medical Center, New York, Department of Obst. \& Gyne, 2004.

[23] MR. Lye \& EIT. Dellinger, “ Timing scheduled cesarean delivery in patient on a teaching versus private service," Adherence to American College of Obstetrician \& Gynecologists guideline and neonatal outcome, AJOG vol. 193, pp. 377-346, 2006.

[24] Tita, Y. Lai, M. Varner, "Timing of elective cesarean delivery at term and neonatal outcomes," NEJM, vol. 360, pp.111-120, 2009.

[25] TC. Okeke, N. Onah, LC. Ikeako, "Maternal \& fetal outcome of elective caesarean section at 37 38 weeks versus 39 completed weeks of gestation in Enugu, Southeast Nigeria," University of Nigeria Teaching Hospital, department of Obstet. \& Gyn., 2013.

[26] FA. Wilmink, CW. Hukkelhoven, S. Lunshof, BWJ. Mol, JAM. Van der Post, DNM. Papatsonis, "Neonatal outcome following elective cesarean section beyond 37 weeks of gestation: a 7-year retrospective analysis of a national registry," AJOG, vol. 202, pp. 250, El-8, 2010. 
[27] R. Dobson, "Caesarean section rate in England and wale hits," BMJ, vol. 323, pp. 951a, 2001.

[28] S, Liu, M. Robert, "Maternal Mortality and Severe Morbidity Associated with Low-Risk Planned Cesarean Delivery Versus Planned Vaginal Delivery at Term," Canadian Medical Association. Journal, Ottawa, vol. 176, pp. 455, 2007.

[29] F. Michael, "Vaginal birth after cesarean Revisited,” NEJM, 2004.

[30] G. Alison, M. David, O. Anthony, "Is vaginal birth after cesarean (VBAC) or elective repeat cesarean safer in women with a prior vaginal delivery?," Department of Obstetrics and Gynecology, Washington University in, 2006.

[31] O. Georg, A. Chukwuemeka, E. Hyacinth, "Maternal and perinatal outcomes of delivery after a previous cesarean section," Department of Obtet.\& Gyne. University of Nigeria Teaching Hospital, 2014.

[32] L. Simpson, "VBAC: is it worth the risk?," Contemporary ObGyn, vol. 48, pp. 27-34, 2003.

[33] JM. Guise, MA. Denman, C. Emeis, "Vaginal birth after cesarean: new insights on maternal and neonatal outcomes," AJOG, vol. 115, pp. 1267, 2010.
[34] Ramachandrappa, L. Jain, "Elective cesarean section: its impact on neonatal respiratory outcome," Clin Perinatol, vol. 35, pp. 373-9, 2008.

[35] AK. Hansen, K. Wisborg, N. Uldbjerg, TB. Henriksen, "Risk of respiratory morbidity in term infants delivered by elective cesarean section: cohort study," BMJ, vol. 336, pp. 85-7, 2008.

\section{Biography:}

Assistant Professor Dr Chro N Fattah: Obtained DGO from Trinity College, Dublin 2001, MRCOG from Royal College of Obstetricians / Gynaecologyist London in 2005, MRCPI from Royal College of Physicians Dublin, Ireland 2006, and obtained MD degree from University college of Dublin Ireland 2012. She is Accredit colposcopies since 2012 from Birmingham. Worked in Dublin Ireland until end of 2012, was a sinore Lecturer for University College of Dublin Medical School for 2 years, then returned and recruited again in university of Suleiman, Medical school, on the November 2012. Have more than 20 publications in international journals .Currently working as a Head of Department of Obstetrics/Gynecology in Medical school Assistant professor and a consultant Obstetrician/Gynecologist in Maternity teaching Hospital study. 